\title{
CORRUPÇÃO NA EMPRESA: BUROCRACIA E UTILIDADE DOS PROGRAMAS DE INTEGRIDADE
}

\section{Thalita Almeida*}

\section{RESUMO}

Esse artigo trata da burocracia e utilidade afeta ao sistema de compliance. O objetivo é demonstrar a essencialidade do movimento anticorrupção e a importância de implementação de programas eficazes nas organizações. O método utilizado foi o dedutivo com pesquisa bibliográfica e breve observação da Ação Penal n. 470, julgada pelo STF. Concluiu-se que, enquanto a burocracia dos programas de compliance esvaziam sua própria razão de existir, subsistem como elementos essenciais: o comprometimento da alta administração/diretoria; a necessária mensuração e mapeamento de riscos; e a disseminação clara e acessível de padrões de conduta, códigos de ética, políticas, procedimentos e sanções.

Palavras-chave: Corrupção; Anticorrupção; Lei n. 12.846/2013; Efetividade dos Programas de Integridade; Burocracia.

\section{CORPORATE CORRUPTION: BUREAUCRACY AND USEFULNESS OF COMPLIANCE PROGRAMS}

\begin{abstract}
This article deals with bureaucracy and utility related to the compliance system. The objective is demonstrate the essentiality of anti-corruption movement and the importance of implementation effective integrity programs in organizations. Deductive method was adopted with bibliographical research, and brief observation of the Penal Action 470, judged by Brazilian Federal Supreme Court. The conclusion is: since bureaucracy and ineffectiveness of compliance programs make their own existence void, subsists as essential elements: commitment of senior management/board of directors; necessary measurement and mapping of risks; and clear and accessible dissemination of standards of conduct, codes of ethics, policies, procedures, and proportional penalties.
\end{abstract}

Keywords: Corruption; Anti-corruption; Law \#12,843/2013; Effectiveness of Integrity Programs; Bureaucracy.

\section{INTRODUÇÃO}

A empresa como agente econômico que move o mundo é palco e, porque não dizer, laboratório de práticas que espraia efeitos em todos os níveis sociais e econômicos de uma sociedade. É no exercício de uma atividade econômica (organizada ou não) que se refletem os

\footnotetext{
* Advogada e Consultora nas áreas de Direito Empresarial, Contencioso Cível, e Contratos; Sócia do escritório Bastos-Tigre, Coelho da Rocha, Lopes e Freitas Advogados, cursando o mestrado em Direito Empresarial pela UERJ; thalita.almeida@bastostigre.adv.br
} 
valores da sociedade, por meio dos seus prepostos e dirigentes que trabalham para o seu fim último, de aferição de lucro.

A partir desse fim, decisões objetivas são adotadas para condução do negócio e, em momentos decisivos, shortcuts devem ser evitados, sob pena de se tornarem solução natural e caminho direto à prática de corrupção.

Nesse contexto, se revela a importância dos programas de integridade que devem funcionar como órgãos de regulação interna para conscientizar, prevenir e combater atos de corrupção de prepostos e dirigentes das empresas.

E no que pertine aos programas de integridade, esse artigo trata da burocracia e utilidade afeta ao sistema de compliance, especialmente, na realidade das empresas brasileiras.

O objetivo é demonstrar a essencialidade do movimento anticorrupção como ferramenta de fortalecimento do Estado Democrático de Direito e, como consequência disso, da necessidade de implantação de programas de integridade eficazes no processo de conscientização dos prepostos e dirigentes das sociedades quanto às práticas de corrupção e omissões que facilitam a corrupção.

Serão observadas, também, as providências não úteis implementadas nesses programas e que, não raramente, terminam burocratizando procedimentos, sem efetivamente combater práticas ilegais.

Reconhecida a imprescindibilidade do compliance, verifica-se que a excessiva burocracia na qual se encontram enredados determinados programas de integridade em nada se relaciona com a finalidade real desse sistema que deve detectar, dissuadir e educar a organização quanto às práticas anticorrupção pela importância que representam no processo de conscientização dos seus prepostos e dirigentes quanto à necessária moralização das relações público-privadas

O método utilizado foi o dedutivo com pesquisa bibliográfica e breve observação da Ação Penal n. 470, julgada pelo Supremo Tribunal Federal.

Para desenvolvimento do tema proposto, foi apresentado um breve histórico sobre o movimento anticorrupção no mundo e, particularmente, no Brasil. No segundo capítulo, foram indicados os principais elementos que devem constituir um programa de compliance efetivo. No terceiro capítulo, foram indicados alguns exemplos de providências burocráticas usualmente aplicadas aos programas de compliance e que não necessariamente lhe conferem 
consistência. Além disso, foi mencionado como exemplo caso real de corrupção envolvendo o Banco Rural e que teve ampla divulgação da mídia. Nesse caso paradigmático, a instituição em questão estava submetida a um consistente programa de integridade que não foi capaz de deter os graves crimes de corrupção praticados pela alta direção.

A conclusão é de que ao passo que a burocracia e inefetividade dos programas de compliance esvaziam sua própria razão de existir, subsistem como âncoras e elementos essenciais que lhes confere consistência e utilidade: (i) o comprometimento da alta administração/diretoria com a dignificação, transparência e moralidade da atuação da empresa; (ii) seguido da necessária mensuração e mapeamento de riscos, por meio da captação da essência da empresa, com a correta verificação das circunstâncias de sua atuação e suas fragilidades; e (iii) por fim, a disseminação clara e acessível de padrões de conduta, códigos de ética, políticas, procedimentos, e sanções proporcionais por descumprimento dessas premissas para todos os prepostos e parceiros da empresa.

\section{CONTEXTO HISTÓRICO}

Muitos pensadores se voltam para a herança portuguesa quando se fala em corrupção no Brasil. Basta pensar em uma abordagem histórica do tema para que Portugal se torne a única origem de todos os males do comportamento corrupto de políticos, empresários e cidadãos (SOUZA, 2017).

A corrupção não foi inventada no Brasil e menos ainda é mal que atinge exclusivamente as terras tupiniquins. A corrupção é prática presente nos países e empresas estrangeiras que, muitas vezes, são consideradas moralmente superiores pelos brasileiros. Esse pensamento é recorrente não só pela pecha de país subdesenvolvido e atrasado que carrega, mas pela noção e sentimento geral que se instalou no Brasil, de que o mercado é virtuoso e o Estado é corrupto. (SOUZA, 2017).

É com a necessária consciência que se deve ter sobre esse mal endêmico que afeta o mundo, as nações e as empresas, que a corrupção deve ser tratada. Não é exagerado admitir que não existe no mundo uma sociedade ou um país completamente livre de corrupção. Até porque, a corrupção tem vários matizes e até a compreensão do que se trata corrupção fica alterada a depender do país e da cultura em questão. Nem a legislação brasileira afeta ao tema exauriu o significado de corrupção, apenas indicando alguns atos e situações para demonstrar 
que o roll não é taxativo, é elástico.

É reconhecendo que a corrupção afeta praticamente todos países de diferentes formas e em diferentes níveis que se deve falar sobre o movimento anticorrupção que veio se intensificando nas últimas décadas. Esse movimento pode ser mais concretamente identificado nos Estados Unidos, no final da década de 70, quando a SEC - Securities Exchange Commission - denunciou o escândalo de Watergate. Naquela ocasião, foi revelado grande esquema envolvendo empresas norte-americanas que pagaram milhões de dólares em propinas para perveter funcionários públicos. (VERÍSSIMO, 2017, p. 149.)

Foi nesse contexto de crise, com repercusão nociva para a reputação das empresas envolvidas no escândalo e prejuízos ao funcionamento do mercado que, no ano de 1977, o Congresso norte-americano editou o Foreign Corrupt Practices Act ("FCPA"). (VERÍSSIMO, 2017). Atualmente, essa legislação norte-americana é referência no movimento anticorrupção:

A criação do FCPA deu-se em razão do episódio conhecido como o "escândalo do Watergate" que levara à denúncia do então presidente norte-americano Richard Nixon e do subcomitê de Corporações Multinacionais do Senado, presidido pelo Senador Franck Church."

A criação do FCPA inaugurou a fase em que se oportunizou às empresas integrantes do esquema a se denunciarem para usufruir da anistia ofertada pelo governo. Esse evento representou marco na história americana, porque os agentes econômicos foram obrigados a rever suas políticas internas e a instaurar programas de compliance para recuperar a reputação afetada pelo escândalo de proporção internacional.

As práticas das empresas americanas que adquiriram negócios localmente ou em
outros países por meio de corrupção de funcionários públicos estrangeiros foram
expostas pela investigação do procurador especial que examinou a campanha para a
reeleição do Presidente Nixon. Em reação às demandas da sociedade, a SEC lançou
um programa de disclousure, anunciando anistia para as empresas que revelassem
ter realizado pagamento indevidos a funcionários públicos estrangeiros, desde que se
comprometessem também a adotar procedimentos internos de compliance
anticorrupção. A extensão das revelações foi chocante: mais de 400 empresas, dentre
as quais 100 entre as maiores do mundo, confessaram ter pago propinas substanciais
no passado. (MARINELA, 2015, p. 18)

Esse histórico confirma a impressão de que a corrupção é nociva em qualquer lugar do mundo e não encontra limites até que seja enfrentada como um problema endêmico que precisa de tratamento objetivo.

Carla Veríssimo comenta que o FCPA foi precursor no combate à corrupção, porque inaugurou o sistema que prevê aplicação extraterritorial da lei anticorrupção e pela preocupação de sancionar as empresas como agentes que trabalham na oferta de propinas 
para funcionários públicos. (2017, p. 151).

Já no final da década de 80, o Congresso norte-americano encarregou o Presidente dos Estados Unidos de negociar tratativas com os países-membros da Organização para a Cooperação e o Desenvolvimento Econômico (“OCDE”) com o objetivo de proibir o pagamento de propinas em operações comerciais internacionais. Essa medida teria sido necessária porque os Estados Unidos se encontravam em desvantagem competitiva no mercado internacional, como consectário das práticas de anticorrupção instauradas pelo FCPA. (MARINELA, 2015, p. 19)

Àquela altura, enquanto nos Estados Unidos se criminalizava a corrupção, em outros países o pagamento de propina para agentes públicos estrangeiros ainda podia ser utilizado como fator de dedução de impostos. Não por acaso, a promulgação de um tratado internacional viria como remédio para reequilibrar o mercado internacional.

O trabalho com a OCDE era essencial pela relevância que a Organização ostentava no cenário internacional, reunindo os países de maior relevância no mercado de investimentos de exportação.

Na realidade, a OCDE já adotara iniciativas relacionadas à prevenção da corrupção -
em 1976 publicou um guia para empresas multinacionais (Guidelines for
Multinational Enterprises). O trabalho de grupos no âmbito da OCDE, para estudo
das legislações nacionais sobre a matéria, bem como a de propostas para ações
concretas levou, em 1994, à adoção de uma Recomendação aos Estados-partes da
organização, no sentido de adotarem medidas efetivas para deter, prevenir e
combater o suborno de funcionários públicos estrangeiros, no âmbito de transações
comerciais internacionais. A recomendação não é juridicamente vinculante, mas teve
grande impacto político, porque foi o primeiro documento internacional em que os
Estados assumiram um compromisso público de adotar medidas concretas para
atingir o objetivo e concordaram com um mecanismo de monitorização da
implementação da recomendação. (VERÍSSIMO, 2017, p. 153)

Com esse raciocínio, a OCDE criou o Working Group on Bribery ("WGB”) que tinha como objetivo integrar diferentes sistemas jurídicos pelo uso da soft law. Em contraponto e também em complementaridade a esse trabalho, a França e a Alemanha entendiam que a criminalização dessas condutas era necessária. Foi nesse ambiente que, em dezembro do ano de 1997, em Paris, se formulou a Convenção sobre o Combate da Corrupção de Funcionários Públicos Estrangeiros em Transações Comerciais Internacionais.

Enquanto isso, no ano de 1996, na América Latina, foi criada a Convenção Interamericana contra a Corrupção da Organização dos Estados Americanos. Referida convenção tem como objetivo impedir que as empresas se utilizem comercialmente da prática de suborno.

Revista de Direito Administrativo e Gestão Pública | e-ISSN: 2526-0073 | Belém | v. 5 | n. 2 |

p. 96 - 117 | Jul/Dez. 2019. 
Ainda no movimento anticorrupção, no ano de 2003, foi criada a Convenção das Nações Unidas como documento que impôs aos Estados-parte a obrigação de criminalizar, investigar e prevenir tanto a corrupção ativa como a corrupção passiva.

Já no ano de 2010, foi editado na Inglaterra o Bribery Act, em um primeiro momento criado para atender os pleitos da OCDE. Essa legislação inglesa é considerada uma das mais completas sobre o tema anticorrupção e trouxe, no seu artigo $7^{\circ}$, como novidade disruptiva, o tipo penal que culpabiliza a falha de uma empresa em evitar a corrupção.

Cada uma dessas convenções criou mecanismos de acompanhamento do desenvolvimento de suas recomendações como, por exemplo, a OCDE que criou o Working Group on Bribery - WGB, a Convenção da ONU que criou a United Nations Convention against Corruption ("UNCAC") e a Convenção Intermaricana que criou o Mecanismo de Seguimiento de la Implantación de la Convención Interamericana contra la Corrupción (MESICIC).

A respeito do tema, Veríssimo dá destaque à observação de Nieto Martin sobre o movimento global:

[...] sobre esta nova estratégia de enfrentamento da criminalidade, que se caracteriza, no âmbito regulatório, por ser uma das demonstrações mais claras do exemplo regulador da global law: confluência de organizações internacionais, que trabalham em rede com atores públicos e privados (empresas multinacionais) e utilizam, para alcançar seus objetivos, ferramentas normativas procedentes do hard law, do soft law e da autorregulação empresarial. (VERÍSSIMO, 2017, p. 158)

O histórico de países considerados desenvolvidos confirma a ideia de que a corrupção, hoje denunciada com mais contundência, não é herança exclusiva de Portugal. A corrupção sempre existiu, o que muda é a percepção das pessoas sobre o tema, em especial, no Brasil, depois que se tornou pauta da imprensa e do enfretamento direto que sofreu, marcadamente por meio de assunção de pactos internacionais e, posteriormente, pela promulgação de legislação própria.

Na última década, o cenário político brasileiro foi tomado por uma enxurrada de denúncias sobre a prática corrupção. O desvio de verbas públicas, o pagamento de propinas em contratos firmados entre a administração pública e empresas privadas, a compra de apoio político no Congresso Nacional, são alguns dos exemplos que podem ser mencionados. Sobre o tema, Carvalhosa comenta que:

No Brasil, a população considera que qualquer autoridade é corrupta e que todas as pessoas jurídicas que contratam com os governos nos três níveis federativos são integrantes desse concurso criminoso, seja pela prática da corrupção comissiva pura, 
seja quando se submete dócil e prazerosamente à corrupção comissiva omissiva. A percepção coletiva é de que as grandes empreiteiras, os grandes laboratórios, as companhias de transporte e de coleta de lixo, as fornecedoras dos órgãos governamentais e das empresas públicas e de economia mista têm o domínio político-administrativo e político-legislativo do País. E, na realidade, é o que ocorre. (CARVALHOSA, 2015, p. 83).

A constatação de Carvalhosa é contundente, mas não menos verdadeira por isso. E, diante das diferentes operações promovidas por agentes públicos fiscalizadores no país, há que se acreditar que alguma lição será aproveitada da sucessão de escândalos denunciados pelos órgãos competentes.

É importante lembrar que, antes de promulgar a Lei n. 12.846/2013, o Brasil ratificou as três convenções de anticorrupção, marcando movimentos políticos que antecederam sua própria legislação. Como retrato dessas providências, pode-se mencionar: (i) a ratificação da Convenção sobre o Combate da Corrupção de Funcionários Públicos Estrangeiros em Transações Comerciais Internacionais da OCDE, por meio do Decreto n. 3.678 do ano de 2000; (ii) a assunção de compromisso junto à Convenção Interamericana contra Corrupção, por meio do Decreto n. 4.410, de 2002; (iii) a ratificação da Convenção das Nações Unidas contra Corrupção, por meio do Decreto n. 5.687, de 2006. (MARINELA, 2015, p. 31)

Depois disso, somente no ano de 2013 foi promulgada a Lei brasileira de n. 12.846, conhecida como Lei Anticorrupção ou da Lei da Empresa Limpa, regulamentada pelo Decreto n. 8.420/2015. Pelo que se observa das datas de promulgação (2013) e regulamentação da respectiva Lei (2015), é possível concluir que a experiência legislativa anticorrupção brasileira reverbera, ainda que tardiamente, processo adotados há algumas décadas em países considerados desenvolvidos.

Pelo que se observa desse histórico, apesar de lento e tormentoso, o combate é dignificante e necessário porque a corrupção enfraquece e diminui o Estado, desacredita as instituições e faz ruir a confiança que o cidadão deveria depositar em suas instituições:

In circumstances of low government legitimacy, citizens try to avoid paying taxes, and firms go underground to hide from the burden of bureaucracy, including attempts to solicit bribes. Using data from the World Values Survey and Transparency International, Uslaner (2010) shows that high levels of tax evasion. Similarly, Torgler's (2006) study of attitudes toward tax evasion in Central and Eastern Europe show that when individuals perceived corruption was high, they were less likely to say that people have an obligation to pay taxes. Thus, one indirect impact of corruption is to persuade people that it is acceptable not to pay taxes because government has been captured by corrupt officials and those who support them. As a consequence, corrupt governments tend to be smaller than more honest governments, everything else equal (Friedman/Johnson/Kaufmann/ZoidoLobaton 2000; Johnson/Kaufmann/McMillan/Wooddruff 2000). Thus in corrupt governments, the individual projects are excessively expensive and unproductive,

Revista de Direito Administrativo e Gestão Pública | e-ISSN: 2526-0073 | Belém | v. 5 | n. 2 |

p. 96 - 117 | Jul/Dez. 2019. 
but the overall size of the government is relatively small. (ROSE-ACKERMAN, 2010, p. 57)

A ideia de que governos corruptos tendem a ser menores ${ }^{1}$ do que governos honestos, ratifica a percepção de que a corrupção é nociva para a sociedade porque afeta negativa e diretamente o Estado Democrático de Direito, uma vez que não se pode falar em democracia em um estado que desvia recursos públicos para satisfazer interesses particulares em detrimento, prejuízo e sofrimento das classes que mais precisam da atuação estatal:

\begin{abstract}
O fenômeno da corrupção relaciona-se diretamente com a eficácia e a credibilidade da gestão pública, atingindo a toda sociedade, seja em menor ou maior escala. Os atos corruptos trazem sérias consequências ao desenvolvimento de um país e contribuem sobremaneira para o agravamento das desigualdades sociais. (MARINELA, 2015, p. 29.)
\end{abstract}

Com todos os seus problemas políticos e sociais, portanto, não por acaso, no ano de 2013, o Brasil ocupou a 72a colocação no ranking dos 175 países mais corruptos no mundo na percepção mundial, conforme divulgado pela International Transparecy. Esse resultado revela que ainda há muito a ser feito, especialmente em razão dos reflexos causados ao desenvolvimento do país. (CARVALHOSA, 2015, p. 83).

No Brasil, em particular, é possível dizer que o movimento anticorrupção aqueceu com a assunção de tratados internacionais, seguido da promulgação e regulamentação da Lei e emergiu de um Estado enfraquecido pela em crise econômica e mergulhado em denúncias de corrupção. Os escândalos de corrupção descreditaram partidos já desgastados politicamente, instituições e figuras que se autointitulavam baluartes da democracia brasileira.

A reboque de uma crise econômica sem precedentes, a constante divulgação de denúncias e escândalos de desvios de recursos públicos para o pagamento de propinas e compra de apoio político no Congresso Nacional despertou (ou reascendeu) na população brasileira o interesse pela política, encontrando seu ápice no ano de 2013 quando ocorreram manifestações públicas que clamaram por mudanças imediatas. O movimento também fomentou no imaginário brasileiro a velha e conhecida crise do "sebastianismo", que representa a crença (portuguesa) de que todos os males e problemas de um país podem ser resolvidos por uma só pessoa, ordinariamente investida no cargo da presidência: o Messias.

Fato é que diversas figuras políticas já avocaram para si a responsabilidade pela

\footnotetext{
${ }^{1}$ Encolhido no sentido de diminuir seu poder de arrecadação de recursos e impostos.

${ }^{2} \mathrm{O}$ sebastianismo representa uma crença, propagada em Portugal, quando do desaparecimento de D. Sebastião (1554-1578). Essa crença pregava que o rei D. Sebastião, desaparecido durante a Batalha de Alcácer-Quibir no norte da África, no ano de 1578, regressaria como um "Messias" que levaria o país a alcançar glórias, apogeus e conquistas.
} 
mudança, mas o que a história revela é que a real evolução e fortalecimento de um Estado, da sua economia e de sua política encontra respaldo e estabilidade quando promovida por instituições robustas e pela conscientização de que os valores e o comportamento da sociedade e dos seus atores sociais não mudam do dia para a noite.

Nesse ponto, há que se refletir: o Estado é corrompido pela empresa, ambiciosa de crescimento e aferição de lucro ou a empresa é corrompida pelo Estado representada por uma classe política amoral e funcionários públicos corruptos e arrecadadores de propinas? Essa é uma questão retórica que esse texto não tem a intenção de responder. $O$ que os estudiosos do tema afirmam e a experiência demonstra é que não há sentido em buscar a origem da corrupção, porque tal enfoque é desimportante. Há necessidade de combate à corrupção, em todas as frentes e em todos os setores da sociedade, marcadamente nas empresas que carregam relevante expressão econômica e são vetores dos valores de uma sociedade.

No que se refere à anticorrupção da empresa, os programas de integridade vêm como ferramentas de combate à corrupção, por representarem um mecanismo de regulação interna e uma associação entre o ente público e a organização privada no interesse comum de dignificar as práticas da economia, do mercado, das licitações e dos contratos públicos em geral.

É com essa missão de detectar, dissuadir e educar que os programas de integridade devem ser encarados. Reconhecendo a empresa como organismo social que manifesta o caráter cultural de uma sociedade é que os programas de integridade nela difundidos são ferramentas essenciais no processo de anticorrupção.

Diante disso, faz-se premente a análise da efetividade e utilidade do compliance como mecanismo que deve impactar a cultura organizacional e comportamental dos seus prepostos e gestores.

\section{PROGRAMAS DE INTEGRIDADE OU COMPLIANCE}

O programa de compliance pode ser descrito como ferramenta, a priori, facultativa que objetiva detectar, dissuadir e educar a organização por meio dos seus prepostos e dirigentes contra prática de atos de corrupção. Bem-sucedido, terá como efeito para a empresa a manutenção de valores, ativos, integridade e boa reputação. O destinatário das normas de compliance é a administração pública, com a qual os agentes econômicos se relacionam 
nos mais diversos setores.

A etimologia da palavra compliance é relevante para compreensão do seu significado e, embora tenha origem na língua inglesa, já se encontra praticamente incorporada ao vocabulário nacional. Para Veríssimo, o significado de compliance pode ser assim definido “[...] substantivo que significa concordância com o que é ordenado; compliant é aquele que concorda com alguma coisa, e to comply with significa obedecer". Em português, compliance pode ser traduzido como programa de integridade e por isso não há incorreção em utilizar as duas formas para se referir ao programa de conformidade; integridade ou compliance, que deve difundir uma cultura de integridade e moralização nas organizações. (VERÍSSIMO, 2017, págs. 90-92)

Conforme restará demonstrado, o sucesso de um programa de integridade está diretamente relacionado ao investimento que se faz na educação dos seus gestores e prepostos, por meio da disseminação de princípios e valores fundamentais na dignificação de pessoas e procedimentos e na conscientização sobre as melhores práticas e cuidados que devem ser adotados no combate à corrupção.

O Decreto n. 8.420 de 2015 tratou de estabelecer no parágrafo $1^{\circ}$ do seu art. $42^{3}$ os

\footnotetext{
${ }^{3}$ Art. 42. Para fins do disposto no $\S 40$ do art. 5o, o programa de integridade será avaliado, quanto a sua existência e aplicação, de acordo com os seguintes parâmetros:

I - comprometimento da alta direção da pessoa jurídica, incluídos os conselhos, evidenciado pelo apoio visível e inequívoco ao programa;

II - padrões de conduta, código de ética, políticas e procedimentos de integridade, aplicáveis a todos os empregados e administradores, independentemente de cargo ou função exercidos;

III - padrões de conduta, código de ética e políticas de integridade estendidas, quando necessário, a terceiros, tais como, fornecedores, prestadores de serviço, agentes intermediários e associados;

IV - treinamentos periódicos sobre o programa de integridade;

V - análise periódica de riscos para realizar adaptações necessárias ao programa de integridade;

VI - registros contábeis que reflitam de forma completa e precisa as transações da pessoa jurídica;

VII - controles internos que assegurem a pronta elaboração e confiabilidade de relatórios e demonstrações financeiros da pessoa jurídica;

VIII - procedimentos específicos para prevenir fraudes e ilícitos no âmbito de processos licitatórios, na execução de contratos administrativos ou em qualquer interação com o setor público, ainda que intermediada por terceiros, tal como pagamento de tributos, sujeição a fiscalizações, ou obtenção de autorizações, licenças, permissões e certidões;

IX - independência, estrutura e autoridade da instância interna responsável pela aplicação do programa de integridade e fiscalização de seu cumprimento;

$\mathrm{X}$ - canais de denúncia de irregularidades, abertos e amplamente divulgados a funcionários e terceiros, e de mecanismos destinados à proteção de denunciantes de boa-fé;

XI - medidas disciplinares em caso de violação do programa de integridade;

XII - procedimentos que assegurem a pronta interrupção de irregularidades ou infrações detectadas e a tempestiva remediação dos danos gerados;

XIII - diligências apropriadas para contratação e, conforme o caso, supervisão, de terceiros, tais como, fornecedores, prestadores de serviço, agentes intermediários e associados;

XIV - verificação, durante os processos de fusões, aquisições e reestruturações societárias, do cometimento de
}

Revista de Direito Administrativo e Gestão Pública | e-ISSN: 2526-0073 | Belém | v. 5 | n. 2 |

p. 96 - 117 | Jul/Dez. 2019.

105 
parâmetros de avaliação do compliance quanto à sua existência e aplicação. Uma breve análise desses parâmetros indicados pelo dispositivo indica elementos essenciais da constituição do compliance que deverá ser adequado à atividade e, inclusive, ao tamanho da organização em que deverá funcionar.

É de crucial relevância reconhecer que o programa de compliance terá maior impacto para o sujeito que não é completamente íntegro e nem completamente corrupto. O programa irá afetar aquele sujeito médio, passível de se corromper em um ambiente inclinado a práticas ilegais, mas, ao mesmo tempo, passível de ser convencido e orientado dentro de uma organização que repudie práticas ilícitas.

Tal constatação é necessária para se compreender que o programa de integridade não será completamente infalível e capaz de dissudiar um sujeito que consciente e premeditadamente busque meios de se beneficiar pessoalmente, movido por interesses particulares e convicções espúrias, aproveitando-se de determinado cargo ou função que exerça em uma empresa.

Nesse ponto, o que se constata é que o programa de integridade efetivo terá que demonstrar capacidade para detectar a prática de corrupção, denunciá-la e mensurar prejuízos para que sejam reparados. Para além disso, deve ser suficientemente eficiente e efetivo na conscientização de prepostos para que a eles seja direcionada uma mensagem clara de intolerância com qualquer ato ou prática de corrupção.

Assim, a providência fundamental de um programa de compliance deve passar pelo treinamento de um ativo valioso, corporificado pelas pessoas que comandam e trabalham na organização. Esse trabalho deve acontecer por meio de treinamentos específicos e circulação de manuais e cartilhas em linguagem acessível, para que tenha o efeito prático de difundir os valores que se pretende sejam apreendidos.

Descrevendo o modelo desenvolvido por Engelhart, Veríssimo explica que o programa de compliance deve ser estruturado em três colunas, que, por sua vez, se subdividem em três pontos:

$1^{a}$ Coluna: Formulação (identificar, definir, estruturar) - Análise de riscos e valoração dos riscos, - Definição de medidas de prevenção, detecção e comunicação, definição dos valores da empresa, - Criação de uma estrutura de compliance; $2^{a}$ Coluna: Implementação (informar, incentivar, organizar), - Comunicação e

irregularidades ou ilícitos ou da existência de vulnerabilidades nas pessoas jurídicas envolvidas; XV - monitoramento contínuo do programa de integridade visando seu aperfeiçoamento na prevenção, detecção e combate à ocorrência dos atos lesivos previstos no art. 5o da Lei no 12.846, de 2013; e XVI - transparência da pessoa jurídica quanto a doações para candidatos e partidos políticos. 
detalhamento das especificações de compliance, - Promoção da observância do compliance, - Medidas organizacionais para criação de processos de compliance; $3^{\mathrm{a}}$ Coluna: Consolidação e Aperfeiçoamento (reagir, sancionar, aperfeiçoar) Estabelecimento de um processo para apuração de violações ao programa de compliance, - Estabelecimento dos critérios para a sanção das violações ao programa de compliance, - Avaliação continuada e aperfeiçoamento do programa. (VERÍSSIMO, Carla. Compliance: Incentivo à adoção de medidas anticorrupção. São Paulo: Saraiva, 2017, p. 277.)

Observadas cada uma das três colunas propostas por Engelhart, será possível identificar elementos essenciais para que um programa de integridade seja considerado efetivo e útil.

O Decreto Lei n. 8.420/2015, por sua vez, elenca uma série de elementos para eficácia do programa de compliance. No entanto, chama atenção o fato de três fatores estarem sempre indicados com primazia nas listas elaboradas pelos estudiosos do tema: (i) comprometimento da alta direção da pessoa jurídica; (ii) necessária mensuração do risk management (ou mapeamento de riscos), com a acurada verificação das circunstâncias e do ramo de atuação da organização e suas fragilidades; e (iii) a disseminação de padrões de conduta, códigos de ética, políticas, procedimentos, bem como das sanções por descumprimento dessas premissas, conforme se verifica a seguir.

\subsection{COMPROMETIMENTO DA ALTA DIREÇÃO DA ORGANIZAÇÃO}

Há que se reconhecer como pilar fundamental de qualquer programa de compliance que os diretores, líderes e dirigentes, enfim todos aqueles que estejam no comando de uma organização, sejam os principais propagadores da cultura de integridade que se pretende reproduzir. Esse primeiro elemento deve estar presente na fase de formulação do programa e também na fase de consolidação e aperfeiçoamento.

O tone at the top ${ }^{4}$ é expressão que simboliza a importância do discurso e do comportamento dos líderes de uma empresa, porque são observados e reproduzidos por seus prepostos e subordinados, uma vez que refletem o comportamento da alta direção de uma empresa.

Na prática, o compromisso da administração com a prevenção da corrupção, por exemplo, deve passar, em primeiro lugar, por uma política de tolerância zero com atos de corrupção, quer em pequenos valores, quer em valores maiores, seja ela ativa ou passiva. Esse exemplo deve ser transmitido hierarquicamente dentro da empresa, as gerentes, que têm contato direto com os empregados, em suas atividades

\footnotetext{
${ }^{4}$ Em tradução livre: "o tom que vem do topo"
}

Revista de Direito Administrativo e Gestão Pública | e-ISSN: 2526-0073 | Belém | v. 5 | n. 2 | 
cotidianas. (VERÍSSIMO, 2017, p. 285.)

Nesse aspecto, não só as atitudes deverão ser copiadas e propagadas, mas também a omissão dos líderes, uma vez também as abstensões reproduzem efeitos e são, naturalmente, reconhecidos como uma autorização ou permissão velada de que determinados caminhos sejam adotados. Quando se constata que se o líder tolera delitos, pequenos ou grandes, em busca de facilidades e supressão de procedimentos burocráticos, essa cultura se alastra na empresa.

Por isso o envolvimento da alta administração é tão relevante tanto na fase formulação do compliance quanto na análise de sua efetividade. Carla Veríssimo esclarece a nocividade do envolvimento da alta administração em delitos com a seguinte reflexão:

O envolvimento da alta direção nos ilícitos contamina completamente o
programa de compliance, porque falta o requisito do comprometimento da alta
gestão, com o que a mensagem não passa aos níveis inferiores da administração.
Esse fato demonstra que ainda que o esforço de compliance não era sério, mas
apenas uma fachada, para funcionar como um "seguro" contra a
responsabilização, um "programa de papel". Além disso, esses são os tomadores
das decisões, suas ações têm o peso mais importante na condução dos negócios.
Por estas razões, pensamos que o programa não poderá ser considerado efetivo,
se houver envolvimento dos dirigentes da empresa nos atos ilícitos praticados.
(VERÍSSIMO, 2017, p. 338) (grifo nosso)

Fazendo referência a Nieto Martins, Veríssimo afirma que quando houver membros da alta administração ou da diretoria de uma empresa envolvida na prática de corrupção há indício de que os investimentos realizados no compliance estão motivados no sistema de minoração de multas e não no combate à corrupção. (VERÍSSIMO, 2017, p. 314)

A conclusão não poderia ser diferente, uma vez que é da alta direção que vem o tom, os valores e os princípios reproduzidos nas organizações. Sob esse aspecto, os valores informados pelos líderes terão impacto de contaminar ou contagiar toda a empresa, sendo por isso, senão o mais importante, mas certamente um dos mais relevantes pilares de um programa de integridade verdadeiramente robusto.

\subsection{MAPEAMENTO DE RISCOS E IDENTIFICAÇÃO: NECESSÁRIA COMPREENSÃO DA ESSÊNCIA DA EMPRESA}

Na sequência, o mapeamento de riscos é elemento fundamental para a estruturação de um compliance efetivo. Tal providência é essencial porque é através desse procedimento que se identifica as fragilidades do agente econômico para ocorrência de delitos. Em termos

Revista de Direito Administrativo e Gestão Pública | e-ISSN: 2526-0073 | Belém | v. 5 | n. 2 |

p. 96 - 117 | Jul/Dez. 2019. 
objetivos, o que se deve levar em consideração no momento de fazer a análise de riscos é identificar aspectos específicos como o porte da organização, área de atuação (ramo da atividade), bem como mensuração de riscos reputacionais e legais na ocorrência de atos ilícitos. (VERÍSSIMO, 2017, p. 279.)

Risk assessment not only provide the company with an overview of risks in order to prevent those risks from materialing but also demonstrate to law enforce personal that the company is pro actively seeking to comply wiht the law (Jeffrey Harfenist \& Saul Pilchen). As with anti-corruption compliance program, the nature and the scope of the risk assessment should be proportionate to the size, activities, costumers, and markets of the organization. A risk assessment will help the determine the scope and nature of the company's anti-corruption compliance program, insuring that resources are allocated to major risk areas and spent where they produce the greatest benefit. As enforcement agencies do not look foundely on "cook cutter" compliance programs or compliance programs that are only found on paper, it is important that any investments made in a compliance program produce effective results while consuming resources that match the benefit gained. Effective anti-corruption compliance programs require an up-to-date inaccurate understanding of the risks the company encounters. Risk assessments should not be a one-time event; regular reviews should be made to insure that resources are properly deployed to deal with involving risks. Not only thus a corporation's business evolve, but the external environment evolves as governments and loss change. (FERGUSON, 2017, p. 4647.)

Conforme orientado por Fergunson, o mapeamento dos riscos é essencial para que os recursos destinados ao programa de compliance sejam alocados nas áreas de maior risco e nas áreas em que produzirá o maior benefício. Por essa razão, o mapeamento de risco deve aferir as áreas de maior fragilidade para detectar deficiências de treinamento, maior ou menor envolvimento de determinadas áreas com órgãos e funcionários públicos, detectar ausência de transparência e controle financeiros, políticas de doações, enfim todas as fragilidades que tornam maior a exposição de determinados setores da empresa para a prática de corrupção.

Márcio de Aguiar Ribeiro também reconhece o mapeamento de riscos como elemento fundamental na construção de um programa efetivo de compliance:

Para que um programa de integridade produza resultados adequados, torna-se premente a necessidade de que a empresa compreenda quais são as áreas e atividades que representam riscos, tanto internos quanto externos, de implicação nas disposições da Lei Anticorrupção. A análise dos denominados riscos de compliance, seja na modalidade pecuniária ou reputacional, é um fato tão relevante que certamente deverá dimensionar a extensão e o alcance do programa de integridade, de maneira que o descompasso existente entre a formatação do programa e riscos envolvidos poderá colocar em xeque o comprometimento da empresa no combate à corrupção. [...] Dentre os fatores de risco, seja internos ou externos, a serem considerados, colocam-se em destaque os seguintes: porte da organização; histórico de violações e apurações; riscos específicos do setor em que a empresa atua; marco legal e regulatório; interação com órgãos governamentais; nível de participação de terceiros e intermediários [...] (grifos nossos) (RIBEIRO, 2017, p. 210.)

Revista de Direito Administrativo e Gestão Pública | e-ISSN: 2526-0073 | Belém | v. 5 | n. 2 |

p. 96 - 117 | Jul/Dez. 2019. 
Disso decorre que o incorreto mapeamento de riscos coloca sob suspeição a credibilidade do programa de integridade que se pretenda implementar. A análise do risco é providência fundamental na formulação do programa de integridade e, posteriormente no seu aperfeiçoamento. Isso porque, porque é a partir da análise e valoração dos riscos que se poderá estruturar o compliance, seja ele complexo ou simplificado, mas efetivamente direcionado à atividade empreendida com a captura da essência da empresa, e é através de sua constante revisão e atualização que não se tornará obsoleto e ultrapassado, sob pena de se tornar imprestável para o que se propõe.

\subsection{DISSEMINAÇÃO DE PADRÕES DE CONDUTA ESPERADOS E DAS SANÇÕES POR DESCUMPRIMENTO}

Já nas fases de implementação e consolidação do programa se encontra o terceiro elemento fundamental que passa pela divulgação dos valores e das condutas esperadas dos funcionários de uma empresa, bem como das sanções impostas por descumprimento. Essa disseminação de valores deve ocorrer de forma clara e objetiva através de cartilhas e manuais que orientem de forma precisa os funcionários.

A título de exemplo, pode ser mencionada, conforme Peixoto e Lopes, a cartilha informativa sobre "práticas de corrupção" circulada pelo grupo Volkswagem. Segundo a autora, o objetivo da cartilha é de chamar atenção e informar os funcionários sobre a questão da corrupção e registrar a importância de uma conduta proba. E prossegue:

O estudo da cartilha traz ótimas sugestões que podem ser adotadas no meio empresarial para evitar corrupção: 1. Em obediência ao princípio da segregação, o relacionamento negocial não pode servir para alcançar vantagem própria ou mesmo para a família do empregado; 2 . Em respeito ao princípio da transparência, as transações comerciais devem ser conduzidas de forma transparente, preferencialmente documentadas por escrito, em particular aquelas referentes a serviços prestados e pagamentos efetuados. 3. Sugere-se que os pagamentos sejam efetuados via transferência bancária, de forma que nunca devem ser feitos em dinheiro. Recomenda-se a verificação da conta dos destinatários a fim de certificar se ela não se encontra em banco localizado em paraíso fiscal (princípio da não utilização de pagamentos em espécie). 4. Não fazer ou aceitar qualquer tipo de contribuição se isto der a impressão de que você só o faz para receber ou conceder algo em troca. 5. Não efetue nenhuma contribuição a funcionários públicos sem solicitar permissão prévia. 6. Nunca efetue transferências ou pagamentos sem ter em mãos uma Nota Fiscal/Fatura. 7. Nos contratos de consultoria, evite pagamentos relacionados a performance. 8. A relação comercial deve sempre ser baseada em um Pedido de Compra ou Contrato formalizado, por escrito, com a descrição detalhada dos serviços a serem prestados. 9. Sempre conduza os negócios de uma forma transparente, de modo que terceiros possam entender suas decisões. 10. Sempre garanta que os serviços

Revista de Direito Administrativo e Gestão Pública | e-ISSN: 2526-0073 | Belém | v. 5 | n. 2 |

p. 96 - 117 | Jul/Dez. 2019. 
prestados e as remunerações sejam proporcionais. (PEIXOTO e LOPES, 2017, págs. 43-44).

Pelo que se verifica da cartilha, foram indicadas providências de ordem prática do que fazer e não fazer em determinadas situações, retirando a subjetividade da conduta que se espera do preposto e indicando situações factíveis para recomendar de forma clara e objetiva de que modo deve se portar em determinadas situações.

Os autores indicam, ainda, outras medidas de anticorrupção elaboradas pelo Grupo Endeavor Brasil, que atua de forma relevante no mercado internacional, em razão do apoio que presta a empreendedores. As práticas recomendadas são de caráter mais genérico, mas igualmente relevantes:

\begin{abstract}
"1. Analisar meticulosamente os riscos operacionais; 2. Gerenciar os controles internos (o profissional dessa área é uma espécie de "Xerife" das normas e procedimentos, em todas as esferas da organização); 3. Desenvolver projetos de melhoria contínua e adequação às normas técnicas; 4 . Analisar e prevenir fraudes (esse profissional tem também papel consultivo; não se trata apenas de cobranças e imposição de mudanças); 5. Monitoramento, junto aos responsáveis pela TI, no que se refere às medidas adotadas na área de segurança da informação; 6 . Realização de auditorias periódicas; 7. Gerenciar e rever políticas de gestão de pessoas, juntamente com os responsáveis pela área de Gestão de Capital Humano; 8. Trabalhar na elaboração de manuais de conduta e desenvolver planos de disseminação do compliance na cultura organizacional; 9. Fiscalização da conformidade contábil de acordo com as normas internacionais (International Financial Reporting StandardIFRS); 10. Leis e adequá-las ao universo da empresa. (PEIXOTO, e LOPES, 2017, p. 45)
\end{abstract}

A lista acima transcrita é excelente exemplo da adoção de procedimentos que devem ser orientados pela organização que busque um programa de integridade efetivo.

Se a conscientização promovida pelo compliance falhar, o programa terá de ser eficiente o bastante para detectar e punir o ato de corrupção verificado para que seja devidamente reportado e tratado com a reparação dos danos que causar. Esse é mais uma importante função do compliance para que seja considerado efetivo, conforme será discutido adiante.

\title{
2.4. EFETIVIDADE DO PROGRAMA DE INTEGRIDADE
}

Verificados os pilares fundamentais do compliance, reconhecendo que não se esgotam neles os elementos para sua constituição ${ }^{5}$, há que se refletir que é a conjugação desses parâmetros que confere efetividade aos referidos programas de integridade.

Conforme afirma Carvalhosa, um programa de integridade depende quase

\footnotetext{
${ }^{5}$ Vide o parágrafo $1^{\circ}$ do art. 42 do Decreto n. 8.420 de 2015.
} 
visceralmente da independência dos procedimentos de auditoria interna, de modo que possa atuar como espécie de "corregedoria proativa da pessoa jurídica". (CARVALHOSA, 2015, p. 328-329).

E, como resultado de um trabalho sério e efetivamente comprometido com a adoção de boas práticas de governança, o compliance deve entregar como resultado de sua consistência providências objetivas, por exemplo:

Dessas contínuas e ininterruptas providências próprias do regime de conformidade
(compliance) resulta a obrigação de revelar os fatos que sejam apurados pela
auditoria interna aos órgãos da administração da pessoa jurídica, de forma a
comprometer e a vincular seus dirigentes (i) no prosseguimento das apurações; (ii)
na cessação imediata das práticas de corrupção interna, privada e/ou pública; (iii) na
exclusão dos seus quadros das pessoas físicas implicadas - incluindo os próprios
dirigentes e funcionários - e (iv) na denúncia aos órgãos públicos competentes para
apuração das responsabilidades penais, administrativas e civis decorrentes das
práticas corruptivas apuradas pela auditoria interna. ${ }^{6}$ ( CARVALHOSA, 2015, p.
330)

No mundo ideal, os programas devem ser pensados com objetivo de prevenir práticas de corrupção nas empresas e não apenas como ferramentas de redução de penas e sanções. Reproduzindo entendimento do autor Nieto Martin, Veríssimo afirma que:

Um programa de compliance será eficaz quando o autor do fato, para a comissão do delito teve que evitar algum dos controles que o programa da empresa estabelecia, ou infringir alguma obrigação específica existente na normativa da empresa para sua comissão. (VERÍSSIMO, 2017, p. 313)

É de fato um importante marcador da efetividade do compliance a constatação de que o próprio programa, por meio das obrigações nele instituídas configurem um obstáculo a ser sobreposto pelo autor do delito, como sinal de que a empresa detém mecanismos de controle que precisam de ser burlados para que se torne possível o cometimento de infrações.

Com essa reflexão, será avaliado de que forma a excessiva burocracia na qual se econtram enredados determinados programas de integridade em nada se relaciona com a finalidade real desse sistema de detecção, dissuasão e educação da empresa quanto às práticas anticorrupção.

\section{BUROCRACIA E UTILIDADE DOS PROGRAMAS DE INTEGRIDADE: A EXPERIÊNCIA BRASILEIRA}

Burocracia não é originalmente um termo negativo. O burocrata é responsável por executar o sistema da atividade pública, possui cargo bem definido e tem de pautar suas ações 
por regulamentos e estatutos inflexíveis, seguindo uma rotina de hierarquia e responsabilidade bem definidas. (COHN, 1982, págs. 128-131)

Assim, a burocracia representa mecanismo para o desenvolvimento de uma sociedade, porque é indispensável ao funcionamento do Estado, no seu papel de gerir os serviços públicos de forma indistinta e padronizada. Não deveria, portanto, ser um termo ruim.

No Brasil, a palavra tem carga negativa remetendo à noção de lentidão, atraso, incompetência, espera indeterminada. Justamente porque a palavra vem carregada de adjetivos negativos tem sido associada a determinados programas de integridade, que em alguns casos têm sido encarados como procedimentos que engessam decisões negociais e demandam a apresentação de documentos e assinaturas que não agregam valor à operação pelo menos não aparente.

Essa percepção pode ser superada pela conscientização da importância do compliance dentro de uma organização. Muitas vezes o desconhecimento é obstáculo à compreensão de determinados procedimentos que são encarados como mera e reducionista burocracia.

Por outro lado, será apenas burocrático e superficial o programa de integridade que não estiver efetivamente engajado com o compromisso de combate à corrupção e não estiver agregado de valores de integridade e dignificação dos processos decisivos de uma organização. Prepostos são perspicazes em notar quando determinada exigência lhes é imposta de forma despropositada, com objetivo único e exclusivo de demonstrar para órgãos fiscalizadores que as regras estão sendo cumpridas, sem que estas reflitam verdadeiramente os valores da empresa. Nessas hipóteses, o programa de integridade servirá apenas como um sistema antimultas ou de minoração de sanções.

Essa percepção pode ser diferente em relação ao compliance se houver efetivo comprometimento com seu valor fundamental de combate à corrupção, bem como se, no processo de implementação, os prepostos forem bem orientados sobre os objetivos, expectativas de condutas, com o claro comprometimento da alta direção nesse processo. Do contrário, todos os procedimentos exigidos pelo compliance ficarão esvaziados de valor sem que recebam a devida credibilidade que lhes deve ser endereçada.

Nesse caso, é fundamental responder às questões eventualmente levantadas em relação aos programas, por exemplo: (i) por que os parceiros e colaboradores devem informar 
a existência de parentesco com funcionário público ou associação com partido político? (ii) por que o preposto deve informar relação de parentesco ou amizade com funcionário de uma empresa concorrente? (iii) por que determinados contratos ou decisões precisam ser ratificadas pelo compliance officer? (iv) por que o preposto não pode emprestar sua senha de acesso ao sistema para um colega de trabalho?; (v) por que determinados cargos e funções devem produzir relatórios sobre suas atividades e reportar constantemente as ocorrências de seu setor para diferentes departamentos da empresa?

Algumas dessas questões deveriam ser retóricas, mas dependendo do interlocutor nem sempre se pode partir da premissa de que a resposta seja óbvia ou clara o suficiente para que o procedimento seja internalizado e respeitado.

Um programa de integridade bem estruturado deverá adotar o cuidado de esclarecer essas questões aos seus funcionários, implementando uma cultura de moralização de procedimentos e decisões junto a seus colaboradores e parceiros. É na implantação que se deve promover a conscientização dos funcionários e stakeholders acerca do compromisso assumido pela organização de adotar condutas transparentes e ilibadas, bem como demonstrar as vantagens de informar, antecipadamente, relações de parentesco com funcionários públicos e prepostos de empresas concorrentes de modo que terceiros possam sempre compreender as decisões adotadas por um funcionário ou um diretor da organização.

Se o processo de implementação do compliance não passar pela etapa de conscientização da importância desses procedimentos, eventuais relatórios produzirão nada mais do que papel, sem refletir as informações relevantes para o funcionamento do programa de conformidade.

Com pesar, há que se reconhecer que muitas vezes o compliance de uma organização não está impregnado dos valores mais essenciais para seu efetivo funcionamento e acabam sendo criados apenas para cumprimento de exigências de fundo legal e procedimental de empresas multinacionais que se veem obrigadas a investir no programa como parte de um pacote de providências de praxe. Tal ocorre, por exemplo com as instituições financeiras. A crítica é recorrente e já ganha espaço nos estudos que tratam de programas de compliance:

As guidelines and frameworks to prevent corruption are becoming more prevalent, there is criticism that increased enforcement is resulting in wasteful overcompliance. Instead of investing in efficient compliance programs, companies are implementing programs intended only to impress prosecutors. (Theresa Tedesco) US Senators Amy Klobuchar and Christopher Coons argue that overcompliance can negatively impact the economy through decreasing product development, export production and expansion of the workforce (Mike Koeler).

Revista de Direito Administrativo e Gestão Pública | e-ISSN: 2526-0073 | Belém | v. 5 | n. 2 |

p. 96 - 117 | Jul/Dez. 2019. 
(FERGUSON, 2017, p. 45)

Essa crítica encontra eco nos escândalos de corrupção denunciados nos últimos anos no Brasil, uma vez que ratifica a impressão de que programas de compliance são produzidos apenas para impressionar promotores e agentes públicos fiscalizadores e não cumprem sua finalidade, porduzindo apenas "espuma", ou seja, material que não reporta efetivamente os riscos, as fragilidades de uma empresa e e não possui capacidade de detectar delitos.

A Ação Penal (AP) n. 470, no qual são partes o o Ministério Publico Federal como autor da ação e como réus Marcos Valério Fernandes de Souza e outros 39 (trinta e nove) acusados, pode ser mencionada como caso paradigmático para fins de análise da utilidade dos programas de integridade no Brasil. Nesse caso, foi julgado complexo esquema de fraudes no Banco Rural. O mensalão, como ficou vulgarmente conhecido, concretiza clássico exemplo de um programa de integridade que, apesar de parrudo, não foi efetivo como mecanismo anticorrupção, uma vez que os próprios agentes de compliance alteraram relatórios para que parecessem corretos e conformes ao programa.

Nos termos da denúncia que deu origem à referida AP n. 470, o Banco Rural teria repassado cerca de $\mathrm{R} \$ 29$ milhões de reais às empresas do publicitário Marcos Valério e cerca de R\$ 3 milhões de reais ao Partido dos Trabalhadores. Tais recursos teriam sido destinados ao pagamento de propinas a políticos, em troca de apoio no Congresso para favorecimento do Governo do então Presidente Luiz Inácio Lula da Silva.7

A reportagem divulgada pelo website G1, relata que os 38 réus processados responderam aos crimes de corrupção ativa, corrupção passiva, evasão de divisas, formação de quadrilha, gestão fraudulenta, lavagem de dinheiro e peculato. Os principais condenados na ação penal eram, nada menos, do que uma acionista e ex-presidente do Banco e um ex-vicepresidente e o vice presidente, à época em exercício. (COSTA, 2012)

A reportagem "Réus do mensalão repetiram alguns crimes várias vezes, aponta PGR", indica números impressionantes sobre a quantidade de vezes que cada um dos acusados teriam cometido os crimes denunciados. Como exemplo dos crimes supostamente praticados: a acionista e ex-presidente do Banco Rural teria praticado 24 (vinte e quatro) vezes o crime de evasão de divisas, 1 (uma) vez o crime de formação de quadrilha, 1 (uma) vez o crime de

\footnotetext{
${ }^{7}$ O website G1/Globo.com noticiou que o STF conclui julgamento de fraudes no Banco Rural e condenou três réus. Disponível em: http://g1.globo.com/politica/mensalao/noticia/2012/09/stf-conclui-julgamento-de-fraudesno-banco-rural-e-condena-3-reus.html. Acesso em: 29 ago.19.
} 
gestão fraudulenta, e 43 (quarenta e três) vezes o crime de lavagem de dinheiro. ${ }^{8}$ Números que impressionam, especialmente quando confrontados com a importância e a magnitude do cargo ocupado. Isso significa que o compliance era inútil.

$\mathrm{O}$ caso demonstra um concreto programa de compliance que não contava com a real adesão da alta direção do Banco, uma vez que os seus principais dirigentes estavam, no entender do Ministério Público, envolvidos no cometimento dos delitos como protagonistas.

Nesse caso do mensalão, é evidente que o programa funcionava como um mero sistema antimultas, sem agregar valor real à instituição financeira e sem sucesso no cumprimento da sua finalidade. É por isso que, para analisar a utilidade do compliance, é necessário reconhecer que o programa deve integrar um ciclo virtuoso de efetivo aperfeiçoamento dos níveis de corrupção devendo contar, precipuamente, com o comprometimento de sua alta administração, sem o que o programa pode ser considerado inócuo.

\section{CONCLUSÃO}

Pelo que se constata das reflexões propostas nesse trabalho, o compliance integra processo imprescindível no combate à corrupção.

Verifica-se, também, que a excessiva burocracia na qual se encontram enredados determinados programas em nada se relaciona com a finalidade real desse sistema de moralização das relações público-privadas. A produção de papel e relatórios são consectários do compliance e servem apenas como escudos de defesa e instrumentos antimultas não estando necessariamente relacionados à sua finalidade central.

Como pilares de sustentação que conferem consistência e utilidade ao compliance encontram-se o: (i) comprometimento da alta administração/diretoria que deve pregar e verdadeiramente atuar de forma digna, transparente e moral exigindo parâmetros equivalentes dos demais setores e níveis da empresa; (ii) a necessária mensuração e o mapeamento de riscos, por meio da captação da essência da empresa, com a correta verificação das circunstâncias de sua atuação e suas fragilidades; e (iii) por fim, a disseminação clara e acessível de padrões de conduta, códigos de ética, políticas, procedimentos, e sanções proporcionais por descumprimento dessas premissas para todos os prepostos e parceiros da

\footnotetext{
${ }^{8} \mathrm{O}$ website g1/Globo.com divulgou que Réus do mensalão repetiram alguns crimes várias vezes. Disponível em: http://g1.globo.com/politica/mensalao/noticia/2012/07/reus-do-mensalao-repetiram-alguns-crimes-variasvezes-aponta-pgr.html. Acesso em: 29 ago.19.
} 
empresa. A falta de qualquer desses elementos nos programas de integridade representa a medida exata para que não se sustentem e percam a sua própria razão de existir.

\section{REFERÊNCIAS}

BRASIL. Supremo Tribunal Federal. Ação Penal n. 470/MG. Rel.: Min. Roberto Barroso. Brasília, 2 de agosto de 2012. Disponível em: http://portal.stf.jus.br. Acesso em 29 ago.2019 CARVALHOSA, Modesto. Considerações sobre a Lei anticorrupção das pessoas jurídicas: Lei n. 12.846/2013. São Paulo: Editora Revista dos Tribunais, 2015.

COHN, Gabriel. (org.) Max Weber: sociologia. 2. ed.. São Paulo: Ática, 1982.

COSTA, Fabiano; OLIVEIRA, Mariana, PASSARINHO, Nathalia e D'AGOSTINO, Rosanne. Julgamento do mensalão: STF conclui julgamento de fraudes no Banco Rural e condena três réus. Veiculado em G1/Globo.com, 06 de setembro de 2012. Disponível em: http://g1.globo.com/politica/mensalao/noticia/2012/09/stf-conclui-julgamento-de-fraudes-nobanco-rural-e-condena-3-reus.html. Acesso em: 29 ago.2019.

FERGUSON, Gerry. The lawyer's role in advising business clients on corruption and anticorruption issues. In.: GLOBAL CORRUPTION: Law, Theory and Practice. Library and Archives Canada Cataloguing in Publication, 2017.

MARINELA, Fernanda; PAIVA, Fernando e RAMALHO, Tatiany. Lei anticorrupção: Lei n. 12.846, de $1^{\circ}$ de agosto de 2013. São Paulo: Saraiva, 2015.

OLIVEIRA, Mariana. Réus do mensalão repetiram alguns crimes várias vezes, aponta PGR. Veiculado em G1/Globo.com, 31 de julho de 2012. Disponível em: http://g1.globo.com/politica/mensalao/noticia/2012/07/reus-do-mensalao-repetiram-algunscrimes-varias-vezes-aponta-pgr.html. Acesso em: 29 ago.2019.

PEIXOTO, Carlos Wendel e LOPES, Luana Francisca Filgueira. A prevenção à corrupção no Direito comparado: mecanismos esposados pelo ordenamento jurídico alemão com o escopo de inibir práticas corruptas e sua possibilidade de aplicação no Direito brasileiro. In.: PORTO, Vinicius e MARQUES, Jader (org.). O compliance como instrumento de prevenção e combate à corrupção. Porto Alegre: Livraria do Advogado, 2017.

RIBEIRO, Márcio de Aguiar. Responsabilização administrativa de pessoas jurídicas à luz da lei anticorrupção empresarial. Belo Horizonte: Fórum, 2017.

ROSE-ACKERMAN, Susan. Chapter4: The Institutional Economics of Corruption. In.: GRAAF, Gjalt de; VON MARAVIC, Patrick; WAGENAAR, Pieter. The good cause: Theorical Perspectives on Corruption. Farminton Hills: Barbara Budrich, 2010.

SOUZA, Jessé. A elite do atraso: da escravidão à Lava Jato. Rio de Janeiro: Leya, 2017.

VERÍSSIMO, Carla. Compliance: Incentivo à adoção de medidas anticorrupção. São Paulo: Saraiva, 2017. Acesso em 29 ago.2019. 